\title{
Factors Affecting the Adoption of mHealth Services among Young Citizen: A Structural Equation Modeling (SEM) Approach
}

\author{
Md. Rakibul Hoque ${ }^{1}$, Mohammad Rezaul Karim², Mohammad Bin Amin ${ }^{3}$ \\ ${ }^{1}$ Assistant Professor, Department of Management Information Systems, University Of Dhaka, BANGLADESH \\ ${ }^{2,3}$ Assistant Professor, Department of Business Administration, Shanto-Mariam University of Creative Technology, BANGLADESH
}

\begin{abstract}
In Bangladesh, nearly everyone has access to a mobile phone and it is increasingly affordable and widespread in all clusters of people have significant impact to extend social relations. The telecom is one of the rapidly growing industries in Bangladesh. Mobile phone is playing a vary significance role with pervasive services. Dissemination of health related information to the general people was a great challenge for this highly populated country, but this problem is going to be erased by application of mobile phone in this regards. In this study attempted to determine and measure the various usages of mobile phone in Bangladesh among the young age group (patients) how they use Mobile phones to solve health related problem. Technology Acceptance Model (TAM) is used as the theoretical underpin to conduct this study. A questionnaire survey method was used to collect data from respondents in different public and private universities of Bangladesh. The data were analyzed using the Partial Least Squire (PLS) method, a statistical analysis technique based on structural Equation Model (SEM). Findings revealed that perceived usefulness $(p<0.05)$ positively predicted the intention to use mHealth services, while perceived ease of use ( $p>$ 0.05) was identified as a less significant factor in the mHealth adoption in Bangladesh. The findings from the study can serve as input to promote citizen's use of mobile phone for better self-management of health.
\end{abstract}

Keywords: mHealth; Bangladesh; Technology Acceptance Model (TAM).

\section{INTRODUCTION}

Today cell phones have become a necessity for almost every person throughout the world. The cell phones ensure the ability to keep in touch with family, business associates, access to email and for other reasons the importance of cell phones is increasing (Aker and Mbiti, 2010). Most probably the advancement in cell phones/smart phones technology takes place speedier than Moore Law's. At the time of inception of cell phones to the public, they were bulk in size, costly, and some even required a base unit that had to be carried along with the phone (Agar, 2013). Perfect reception quality from the network was a major problem in general, and early cell phones could only be used in certain locations were the signal was particularly strong. It will be hardly found like Bangladesh in the world that can guarantee each one of its inhabitants can get a cell phone signal - no matter where they are in the country with a population of over 156 million. There are over six nationwide independently owned cell phone companies competing for business. After the introduction of Cell Phone in Bangladesh in 1993, the total number of Mobile Phone subscriptions has reached 121.860 million at the end of January 2015 (BTRC, 2015).

As technology advanced, the difficulties in using of cell phone have dramatically reduced, call reception has improved significantly due to the use of satellites and wireless services, including voice communication, messaging, personal information management (PIM) applications and wireless communication capability (Zheng and Ni, 2010). The results of such new uses of smart-phone in Bangladesh have also helped to develop various projects plan for scaling up. In Bangladesh, some of these mobilephone based services include mobile money (i.e. OboPay/ Grameen's Bank-a-Billion project), healthcare (i.e. Manoshi), education (i.e. Janala) and information or helpline services (i.e. Pallitathya Help-Line).The commencement of various applications of mobile phones in healthcare has transformed healthcare delivery around the world by making it more accessible and reasonably priced across electronic markets (Akter et al., 2010).

In Bangladesh, nearly everyone has access to a mobile phone, and it is increasingly affordable and widespread in all clusters of people have significant impact to extend social relations. In this study attempted to determine and measure the various usages of mobile phone in Bangladesh among the young age group (patients) how they use Mobile phones to solve health related problem.

\section{The ObJectives OF THE Study}

The objective of the study is to understand why and how people use mobile phone/Smartphone to get health services and identify the impact and effects of mobile phone to solve health related problem on youth in Bangladesh. 


\section{LITERATURE REVIEW}

Mobile health, more commonly known as mHealth, incorporates a wide range of programs. Although definitions vary, the World Health Organization's Global Observatory for eHealth defines mHealth as "medical and public health practice supported by mobile devices, such as mobile phones, patient monitoring devices, personal digital assistants (PDAs), and other wireless devices" (WHO, 2011, p. 6).In broad, it is defined as the use of portable devices with the capability to create, store, retrieve, and transmit data in real time between end users for the purpose of improving patient safety and quality of care (Consulting, 2009).Furthermore, the mHealth Alliance defines "mHealth stands for mobile-based or mobileenhanced solutions that deliver health. The ubiquity of mobile devices in the developed or developing world presents the opportunity to improve health outcomes through the delivery of innovative medical and health services with information and communication technologies to the farthest reaches of the globe". Iluyemi (2010) extended this definition by focusing on any wireless technologies (e.g., Bluetooth, GSM, GPRS/3G, Wi-Fi, WiMAX) to transmit various health related data contents and services through mobile devices such as mobile phones, smart-phones, PDAs, laptops and Tablet PCs. However, this definition has targeted only health workers as the sole users of mobile health services, but there many mHealth services which are being used by both patients and health workers, such as, mobile telemedicine services in India, Bangladesh and Mexico.

Focusing on such mHealth platform, Akter et al. (2010) defined it "as a personalized and interactive service whose main goal is to provide ubiquitous and universal access to medical advice and information to any users at any time over mobile platform". West Wireless Health defined "The delivery of health care services via mobile communication devices such as cell phones. Applications range from targeted text messages to promote healthy behavior to wide-scale alerts about disease outbreaks. The proliferation of cell phones across the globe, even in locales without basic health care infrastructure, is spurring the growth of mHealth in developing countries."

The activities of mHealth have grown in popularity around the world. A global survey of 114 nations undertaken by the World Health Organization found that many countries have established mHealth initiatives (WHO, 2012). Not surprisingly, in the adoption of mHealth, the differences between developed and developing nations vary. Africa had the lowest rate of mHealth adoption while North America, South America, and Southeast Asia showed the highest adoption levels. A number of countries have initiatives in the pilot stage or have informal activities that are underway. Analysts predict that the size of the worldwide mobile health market will reach US $\$ 23$ billion by the year of 2017 . They forecast that Europe and Asia-Pacific will have the largest markets followed by North America. Latin America and Africa will have the smallest markets (Vishwanath et al., 2012).

In the USA, Smartphone is the most commonly used devices for communication and almost $27 \%$ of the consumers' use Smartphone's for online activities. Accordingly surveys more than 10 million users in USA use Smartphone to search for health information and facilities. There are a number of Impact of Smartphone's on Society 221 mobile applications to facilitate the users to promote alternative treatment options, provide price comparisons and validate and manage prescriptions (Byrne, 2010).At present more than 40,000 mobile health apps available for tablets and Smartphone's, and more than 500 health projects underway worldwide with the emphasis to use Smartphone apps in the health sector (Larid, 2012).

A survey was conducted on a small number of US healthcare students, administrators, providers, and nurses by a software company and the reports shows that almost $83 \%$ use Smartphone's to access, $72 \%$ use Smartphone's to write notes and memos, $50 \%$ use it for drug references, $28 \%$ use Smartphone to access clinical decision support tool and 13\% to view medical images (Wyatt and Krauskopf, 2012).The current use and development of mHealth applications is on the rise in the developing world. mHealth applications are being used in the developing world to improve health education and awareness, diagnostic treatment and support services, data collection and remote monitoring services, surveillance, emergency medical services and other healthcare services. Although there have been considerable benefits of mHealth services, they have encountered numerous challenges and difficulties as a newly emerging phenomenon. Some of the challenges in the adoption of mobile technology in healthcare include confidentiality. Even as much as we are encouraging the use of mobile health, issues like confidentiality of patient information/data and diagnosis should be addressed. Patients will not be comfortable using any health application until they are assured of privacy and security protection. Mindset adjustment is another challenge where some patients and also physicians are used to the traditional healthcare system, and it's hard for them the embrace the new technologies in health. Also, not all patients understand English in the rural areas the some of the patients and doctors communicate in their mother tongue. The patients should be empowering with medical knowledge in the everyday language.

Lack of clear regulation and policies in the mHealth ecosystem is delaying the comprehensive and widespread of the use of technology in healthcare. There is the need for the creation of policies and frameworks that encourage the development of innovative mHealth solutions and harmonize the regulation between the delivery of traditional healthcare services and mobile health services. mHealth brings more than new technologies. It facilitates a 
new way that enables health enterprises to engage patients, improve outcomes and lower costs. It's clear that technology is giving the healthcare industry a much-needed upgrade, from medical translation tools to mobile apps that help patients live healthier lives.

\section{mHealth Services in Bangladesh}

At recent scenario, in Bangladesh there are numerous sectors working for mHealth including Government, Mobile Phone Companies, and NGOs. A subsequent study of innovations for health in Bangladesh provided more detailed information on a number of these initiatives (Bloom et al., 2013). Figure 1 shows the mHealth services in Bangladesh.

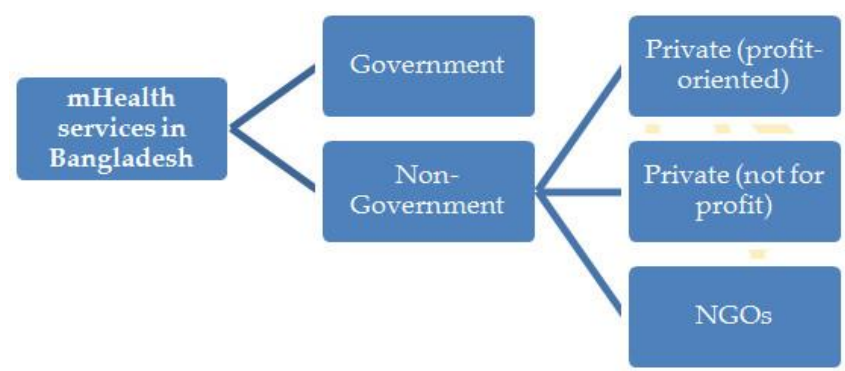

Figure 1: mHealth Services in Bangladesh

\section{Government}

In the Movement of Digital Bangladesh, Ministry of Health and Family Welfare (MoHFW) has assigned various responsibilities for implementing the health component to the Director General of Management Information Systems, in the Directorate General of Health Services (DGHS).(43) The government is implementing an ambitious strategy for integrating ICTs into the public health system (Azad, 2013). To implement the work both the government and development partners have agreed to develop a common framework, as well as funding. The government has also begun to establish a regulatory framework. As part of the government plan to develop an ICT-informed health system, a mobile phone health service which involves government-run upazila (47) (the second lowest tier of regional administration in Bangladesh) health complexes and district hospitals using mobile phones as a local 24hour call centre has been developed. (46) Local communication channels are also being used to create consciousness and inform people of the relevant issue.

\section{Non-Government}

Bangladesh's public sector has been struggling to cover its vast population for healthcare. NGOs and private sector providers are stepping in this regards. Private sector e-Health and mHealth initiatives in Bangladesh is remarkable because in the mHealth various telecom firms, NGOs, and other private organizations playing significance role. The organization involved in the eHealth and mHealth project now include:
- the mobile telephone operators;

- for-profit and not-for-profit companies specializing in health-related added-value content for mobile telephones including SMS messages and advice lines;

- producers and distributors of health-related commodities such as pharmaceuticals, food supplements, products for babies and so forth;

- $\quad$ service delivery NGOs which are integrating ICTs into their work; and

- University research departments which are developing new applications in response to prizes and challenge funds.

The development of a wide variety of e-Health and mHealth innovations has been stimulated by funding from a number of channels which include bilateral support to NGOs, special donor for supporting e-Health and mHealth, and challenge funds operated by large foundations. (51) In addition, the mobile phone operators have been actively seeking new sources of revenue as they compete in a market with very high levels of mobile phone coverage.

Various mHealth Projects run by NGO, Mobile Operators

- MAMA Bangladesh: MAMA Bangladesh is the Bangladesh Secretariat of the Mobile Alliance for Maternal Action (MAMA), a global alliance for improving maternal and child health through mobile technology. MAMA Bangladesh leverages on the wideranging partnership with government agencies, private sector, and NGOs. The Partnership has been built between D.Net and a number of reputed institutions in Bangladesh for reaching mHealth facilities across the country, particularly in rural areas and urban slums.

- Aponjon mHealth service: Aponjon mHealth service, an initiative in Bangladesh by USAID under the patronage of Mobile Alliance for Maternal Action (MAMA), made a soft-launch after a successful pilot operation. Already 540 community agents of five outreach partners of the initiative have started enrolling clients in 17 districts, the first service under the Aponjon brand that provides health information service to new mothers through mobile phone.

- Manosh Innovation (mHealth Project): BRAC's Manoshi gained considerable traction using community health workers to aid poor women in child birth and neonatal healthcare. Currently piloted in the urban slums under Manoshi (MNCH Urban) Programme, the initiative intends to digitize the health services by collecting, recording, preserving household information thus creating a real-time virtual database. The database helps in speeding up service delivery process to the target population. The program intends to scale up mHealth project to rural areas by the first quarter of 2013.

- Mobile operator's mHealth Services: No doubt, mHealth has growing interest to the mobile operator. The provision of health-related services via mobile communications reflects a growing body of evidence that 
demonstrates the potential of mobile communications to radically improve healthcare services. The service reaches even in some of the most remote and resource-poor environments. In Bangladesh, Grameenphone is already providing "789 Health-line Services" to all subscribers where consultations are available over the phone for medical advice, emergency advice, information on drugs and lab test advice. Banglalink also has recently launched 'Healthlink Service' for its subscribers, according to a press statement. Under this service, Banglalink subscribers will now be able to get health counseling services through a call center managed by Synesis IT. (Blink website)All Robi Customers can dial 789 and get connected to live call center agents who will be answering their health related queries and questions (from 8 am to $7 \mathrm{pm}$ ). The agents will be specialized doctors who will provide instant solution/suggestion to the queries or will call back to the customer if the solution is complex and needed to be consulted before answering.

\section{THEORETICAL FrAMEWORK}

There are many theories used in IS research (Wade 2009).We are interested only in theories about technology adoption. The major used technology adoption theories are the technology acceptance model (TAM) (Davis 1986, Davis 1989, Davis et al. 1989), theory of planned behaviour (TPB) (Ajzen 1985, Ajzen 1991), unified theory of acceptance and use of technology (UTAUT) (Venkatesh et al. 2003), DOI (Rogers 1995), and the TOE framework (Tornatzky and Fleischer 1990). The DOI and the TOE framework are usually used to study technology adoption at the firm level. The TAM, TPB, and UTAUT are at the individual level. TAM derived from the Theory of Reasoned Action explains user acceptance and usage behavior of information technology. According to the TAM, the actual use of a system depends on the intention to use it. The model (Figure 2) explains that Perceived Usefulness (PU) and Perceived Ease of Use (PEU) directly influence the intention to use the technology.

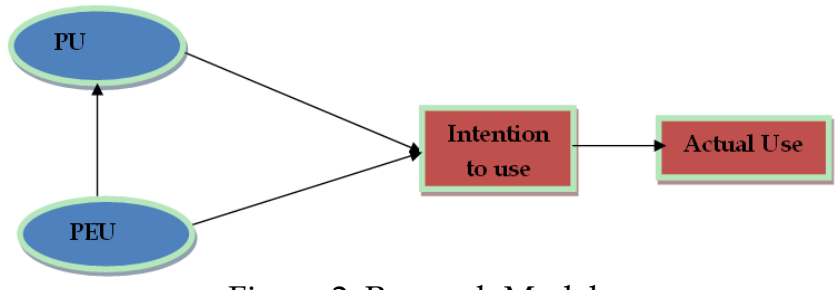

Figure 2: Research Model

\section{Perceived Usefulness (PU)}

Perceived usefulness is defined as the degree to which "a person believes that the use of the system will enhance his or her performance" (Davis, 1989). Previous Research found a strong relationship between PU and technology adoption. Based on the existing literature, we proposed the following hypotheses:
H1: Perceived usefulness has a positive influence on the intention to adopt mHealth services among young citizen in Bangladesh.

\section{Perceived Ease of Use (PEOU)}

Perceived ease of use is defined as the degree to which "the degree to which person believes that using a particular system would be free of effort."(Davis, 1989). It is argued that PEOU influence the user intention to accept the technology. Consequently, the following hypothesis is suggested:

H2: Perceived ease of use has a positive influence on the intention to adopt mHealth services among young citizen in Bangladesh.

TAM also suggests that perceived ease of use influence the perceived usefulness of the technology. The easier it is to use a technology, the greater the expected benefits from the technology. Based on these arguments, we propose the following hypothesis:

H3: Perceived ease of use has a positive influence on perceived usefulness of mHealth services among young citizen in Bangladesh.

The relationship between intention to use and actual use of technology in TAM model are also empirically examined in the different study. Therefore, we propose the following hypothesis:

H4: Intention to use has a positive influence on actual use of $m$ Health services among young citizen in Bangladesh.

\section{Methodology}

\section{Measurement}

All items intended to measure the variables in this study were adopted from previously validated instruments. PU and PEOU were measured with four items adapted from Davis et al (1989).Intention to adopt mHealth and actual use of mHealth with three items was adapted from (Venkatesh and Morris, 2000).

\section{Questionnaire Design and Data collection}

The data for the study was gathered through a structured questionnaire. The questionnaire was divided into Part A and B. Part A contains the demographic information such as gender, age, marital status, Mobile usage experience. Part B includes previously validated questionnaires for the different constructs, using a 5-point Likert ranging from (1) "strongly disagree" to (5) "strongly agree". The questionnaire was distributed to 150 young citizens in Dhaka city, Bangladesh. Out of 150 questionnaires, 144 were returned to the researcher. However, seven questionnaires were removed because they included missing values for at least 1 of the questions.

Data Analysis 
Data were analyzed by Smart PLS software, a technique of Structural Equation Model, for statistical analysis. Development of Structural Equation Model (SEM) is a systematic process. Several steps should be chronologically followed. At first one need to specify the model. In building correct model, two different kinds of variables have to be used: endogenous and exogenous. The Distinction between these variables depends on whether they regress on another variable or not. After the specification of model-free parameters are estimates. Partial least squares regression (PLS regression) is a statistical method that bears some relation to principal components regression; instead of finding hyper planes of minimum variance between the response and independent variables, it finds a linear regression model by projecting the predicted variables and the observable variables to a new space. Because both the $X$ and $Y$ data are projected to new spaces, the PLS family of methods are known as bilinear factor models. Smart PLS is a software application for (graphical) path modeling with latent variables (LVP). The partial least squares (PLS)method is used for the LVP-analysis in this software.

\section{FINDINGS}

\section{Validity and Reliability of the Instrument}

Validity and reliability of the measures should be established before testing the hypothesis (Bagozziet al., 1991). Content validity in this study should be relatively acceptable since the questionnaire was developed based on extensive review of relevant literature. To test convergent validity, CR, factor loading, and AVE (Average Variance Extracted) are examined. AVE measures the percentage of variance captured by a construct by showing the ratio of the sum of the variance captured by the construct and measurement variance. It is acceptable if individual item factor loading is greater than 0.7, CR exceeds 0.7, and AVE exceeds 0.5.

Table 1- Cross-loading

\begin{tabular}{|l|c|c|c|c|}
\hline & ACT & INT & PEU & PU \\
\hline ACT1 & $\mathbf{0 . 8 3 5 9}$ & 0.6256 & 0.6715 & 0.4510 \\
\hline ACT2 & $\mathbf{0 . 9 1 6 5}$ & 0.7455 & 0.7392 & 0.4721 \\
\hline ACT3 & $\mathbf{0 . 9 2 6 2}$ & 0.7863 & 0.8028 & 0.5267 \\
\hline INT1 & 0.6668 & $\mathbf{0 . 8 3 9 2}$ & 0.6967 & 0.3923 \\
\hline INT2 & 0.6877 & $\mathbf{0 . 8 7 8 9}$ & 0.7252 & 0.3438 \\
\hline INT3 & 0.7692 & $\mathbf{0 . 9 1 0 3}$ & 0.7656 & 0.4239 \\
\hline PEU1 & 0.8218 & 0.7804 & $\mathbf{0 . 8 8 1 8}$ & 0.4900 \\
\hline PEU2 & 0.6419 & 0.6666 & $\mathbf{0 . 8 3 8 3}$ & 0.3604 \\
\hline PEU3 & 0.6007 & 0.6004 & $\mathbf{0 . 7 8 3 4}$ & 0.2748 \\
\hline PEU4 & 0.7278 & 0.7632 & $\mathbf{0 . 8 9 5 8}$ & 0.4320 \\
\hline PU1 & 0.4464 & 0.4124 & 0.4057 & $\mathbf{0 . 8 0 1 7}$ \\
\hline PU2 & 0.3346 & 0.2420 & 0.2775 & $\mathbf{0 . 7 4 8 8}$ \\
\hline PU3 & 0.4390 & 0.3424 & 0.4166 & $\mathbf{0 . 8 1 3 1}$ \\
\hline PU4 & 0.4746 & 0.3707 & 0.3534 & $\mathbf{0 . 8 0 3 4}$ \\
\hline
\end{tabular}

Table 1 shows the factor loading. Factor loading ranged from .7488 to .9262 and AVE ranged from .62 to .79 is acceptable range. The reliability tests are conducted to measure internal consistency of data and to test collected data and the instrument used to collect the data are reliable. Cronbach's alpha is estimated for checking internal data consistency which is appropriate for instruments such as the 5 point Likert scale (Ary et al, 2002). The recommended Cronbach's alpha value is greater than 0.70 , which indicate strong internal reliability.

Table 2- The measurement model

\begin{tabular}{|c|c|c|c|c|r|}
\hline Constructs & Items & Loadings & CR & $\begin{array}{c}\text { Cronbach's } \\
\text { Alpha }\end{array}$ & AVE \\
\hline Actual Use & ACT1 & 0.83 & 0.92 & 0.87 & 0.79 \\
\hline & ACT2 & 0.91 & & & \\
\hline & ACT3 & 0.92 & & & 0.76 \\
\hline $\begin{array}{c}\text { Intention } \\
\text { to Use }\end{array}$ & INT1 & 0.87 & 0.90 & 0.84 & \\
\hline & INT2 & 0.83 & & & 0.72 \\
\hline & INT3 & 0.91 & & & \\
\hline $\begin{array}{c}\text { Perceived } \\
\text { Ease of Use }\end{array}$ & PEU1 & 0.88 & 0.91 & 0.87 & \\
\hline & PEU2 & 0.83 & & & 0.62 \\
\hline & PEU3 & 0.78 & & & \\
\hline & PEU4 & 0.89 & & & \\
\hline $\begin{array}{l}\text { Perceived } \\
\text { Usefulness }\end{array}$ & PU1 & 0.80 & 0.87 & 0.80 & \\
\hline \multicolumn{7}{|l|}{ PU2 } & 0.74 & & & \\
\hline \multicolumn{7}{|l|}{ PU3 } & 0.81 & & & \\
\hline & AVE: Average Variance Extracted, & \\
\hline & CR=Composite Reliability & \\
\hline
\end{tabular}

The Cronbach's alpha values (Table 2) for research factors ranged from 0.80 to 0.87 , which indicates adequate internal consistency associated with all measures according to Nunnally and Bernstein's (1994) guidelines. The internal reliability was also evaluated by considering composite reliability where the level of 0.70 as an indicator for acceptable internal consistency (Hair et al. 1995).

Table 3-Correlation matrix and square root of the AVE

\begin{tabular}{|l|c|c|c|c|}
\hline & ACT & INT & PEU & PU \\
\hline ACT & 0.89 & & & \\
\hline INT & 0.81 & 0.88 & & \\
\hline PEU & 0.83 & 0.83 & 0.85 & \\
\hline PU & \multicolumn{2}{|c|}{0.54} & 0.44 & 0.47 \\
\hline
\end{tabular}

Note: ACT=Actual Use, INT=Intention to Use, PEU=Perceived Ease of Use, PU=Perceived Usefulness In general convergent and discriminant validity are considered to be satisfactory when measurement items load high on their respective constructs and low on other constructs (Table 3).

\section{The Structural Model}

The results of the hypotheses testing where the bootstrapping procedure was used to estimate the significance of the path coefficients are displayed in Table 4. Perceived usefulness (PU) was significantly 
Asian Business Review, Volume 5, Number 2/2015 (Issue 11)

ISSN 2304-2613 (Print); ISSN 2305-8730 (Online)

related to intention to use mHealth $(B=.8008, t=24.5229$, $P<0.05)$ and Perceived ease of use was also significantly related to Perceived usefulness $(B=.479, t=6.6589$, $P<0.05)$. However, Perceived ease of use (PEOU), had no significant relationships on intention to use mHealth services $(B=.066, t=1.3637, P>0.05)$.

Table 4 Structural Model

\begin{tabular}{|l|c|c|c|}
\hline & B & T Statistics & Comments \\
\hline INT -> ACT & 0.8089 & 37.1264 & Supported \\
\hline PU -> INT & 0.8008 & 24.5229 & Supported \\
\hline PEOU -> PU & 0.479 & 6.8589 & Supported \\
\hline $\begin{array}{l}\text { PEOU -> } \\
\text { INT }\end{array}$ & 0.066 & 1.3637 & $\begin{array}{c}\text { Not } \\
\text { Supported }\end{array}$ \\
\hline & \multicolumn{2}{|l|}{$\begin{array}{l}\text { R Square for INT }=.654, \\
\text { R Square for ACT }=.696\end{array}$} & \\
\hline
\end{tabular}

Finally, the study found a significance relationship between intention to use mHealth and actual use of mHealth $(B=.8089, t=37.1264, P<0.05)$

\section{CONCLUSION}

Mobile technologies are widely available and can play an important role in heal-thcare at the regional, community, and individual levels. Unquestionably, in Bangladesh mHealth is going to be a growing platform for healthcare services but in the adoption this services to the common people leftovers a challenge. mHealth opens up new avenues for doctors to make health-care even more patient-centered, and to overcome difficulties posed by the location or timing of appointments. This study provides an overview of mHealth services in Bangladesh and addresses the role of mHealth applications in improving healthcare delivery, especially to the youth age who are the most common users of Smartphone. mHealth can improve patient care, treatment and safety for example through early disease diagnosis, improved patient compliance, and improved disease testing.

\section{REFERENCES}

Agar, J. (2013).Constant touch: A global history of the mobile phone. Icon Books.

Ahmed, T., Bloom, G., Iqbal, M., Lucas, H., Rasheed, S., Waldman, L., \&Bhuiya, A. (2014). E-health and M-Health in Bangladesh: Opportunities and Challenges.

Ajzen, I. (1991). The theory of planned behavior.Organizational behavior and human decision processes, 50(2), 179-211.

Aker, J. C., \&Mbiti, I. M. (2010).Mobile phones and economic development in Africa.Center for Global Development Working Paper, (211).

Akter, S., D'Ambra, J., \& Ray, P. (2011). Trustworthiness in mHealth information services: an assessment of a hierarchical model with mediating and moderating effects using partial least squares (PLS). Journal of the American Society for Information Science and Technology, 62(1), 100-116.

Bloom, G.; Sarwar, R.; Standing, H.; Begum, T.; Rahman, S. and Wilkinson, A. (2013) Innovations for Health in Bangladesh, Dhaka: Srijon, http://srijon.grminternational.com/wpcontent/uploads/2014/03/Srijon-scoping-study.pdf
BTRC (2015). Mobile Phone Subscribers in Bangladesh, Bangladesh Telecommunication Regulatory Commission Report

Byrne, J. (2010). Healthcare "Apps" exploding in Mobile, are you ready. V-Fluence Blog.

Chowdhury, M., \& Rahman, M. (2015). Consumer Attitude Towards the Cell Phone: A study on Young Generations of Chittagong Metropolitan City, Bangladesh. Asian Business Review, 3(3), 16-20.

Consulting, V. W. (2009). mHealth for development: the opportunity of mobile technology for healthcare in the developing world. Washington Dc and Berkshire, UK.

Davis, F. D., Bagozzi, R. P., \&Warshaw, P. R. (1989). User acceptance of computer technology: a comparison of two theoretical models. Management Science, 35(8), 982-1003.

Hoq, M. (2013). Regional Differentials of Age at First Marriage among Women in Bangladesh. Asian Journal Of Applied Science And Engineering, 2(2), 76-83.

Kay, M., Santos, J., \&Takane, M. (2011).mHealth: New horizons for health through mobile technologies. World Health Organization, 66-71.

Laird, S. (2012). How smartphones are changing healthcare, http:/ / mashable.com/2012/09/26/smartphones-healthcare-infographic/

Neogy, T. (2014). Evaluation of the Companies' Performance: A Study on Mobile Telecommunication Companies in Bangladesh.American Journal Of Trade And Policy, 1(3), 33-38.

Rogers, E. M. (1995). Diffusion of Innovations: modifications of a model for telecommunications. In Die Diffusion von Innovationen in der Telekommunikation (pp. 2538).Springer Berlin Heidelberg.

Tania F and Sultana N. 2014. Health Hazards of Garments Sector in Bangladesh: The Case Studies of Rana Plaza Malaysian Journal of Medical and Biological Research, 1, 111-117.

Tornatzky, L. G., Fleischer, M., \&Chakrabarti, A. K. (1990).Processes of technological innovation.

Venkatesh, V., \& Morris, M. G. (2000). Why don't men ever stop to ask for directions? Gender, social influence, and their role in technology acceptance and usage behavior.MIS Quarterly, 115-139.

Venkatesh, V., Morris, M. G., Davis, G. B., \& Davis, F. D. (2003). User acceptance of information technology: Toward a unified view. MIS Quarterly, 425-478.

Vishwanath, S., Vaidya, K., Nawal, R., Kumar, A., Parthasarathy, S., \&Verma, S. (2012). Touching lives through mobile health: Assessment of the global market opportunity.Price water house Coopers.

World Health Organization.(2011). mHealth New horizons for health through mobile technologies. 2011. Cerca con Google.

Wyatt, T., \&Krauskopf, P. (2012). E-health and nursing: using smartphones to enhance nursing practice. Online Journal of Nursing Informatics (OJNI), 16(2).

Zablon KL. 2014. Animal Health Governance and Services: A Case of Pastoralists in Ngorongoro District, Tanzania Schol of Rural Development, Sokoine University of Agriculture, Tanzania.

Zheng, P., \& Ni, L. (2010).Smart phone and next generation mobile computing. Morgan Kaufmann.

$$
-0 \text {-- }
$$

